\title{
CARACTERIZAÇÃO REOLÓGICA DA INTERAÇÃO ELETROSTÁTICA ENTRE CONCENTRADO PROTEICO DE SORO E PECTINA EM FUNÇÃO DA APLICAÇÃO DE ULTRASSOM
}

\author{
K. M. ALBANO ${ }^{1 *}$, V. R. N. TELIS ${ }^{1}$ \\ ${ }^{1}$ Universidade Estadual Paulista “Júlio de Mesquita Filho", Departamento de \\ Engenharia e Tecnologia de Alimentos \\ *e-mail: kivia_engalimentos@yahoo.com.br
}

\begin{abstract}
RESUMO
Proteínas e polissacarídeos estão presentes em conjunto em muitos tipos de sistemas alimentícios e ambos contribuem para a estrutura, textura e estabilidade através de seu comportamento espessante ou gelificante ou de sua atividade de superfície. Misturas de proteínas e polissacarídeos são interessantes, pois o comportamento reológico das misturas pode diferir bastante do comportamento dos compostos puros. Além disso, a aplicação de ultrassom de alta intensidade com o objetivo de alterar propriedades funcionais dos biopolímeros também vem sendo estudada. O objetivo do trabalho foi avaliar a interação eletrostática do par concentrado proteico de soro de leite e pectina de alto teor de metoxilação em função da razão proteína:polissacarídeo com e sem a aplicação de ultrassom, buscando identificar as microestruturas formadas por meio de reologia, microscopia ótica e avaliação visual no $\mathrm{pH}$ 3,5. O modelo Lei da Potência ajustou-se bem aos dados $\left(\mathrm{R}^{2}=0,9\right)$ e o par apresentou comportamento pseudoplástico $(\mathrm{n}<1)$ tendendo ao Newtoniano $(\mathrm{n}=0,9)$, o índice de consistência $(\mathrm{K})$ diminuiu com $\mathrm{o}$ aumento da proporção de proteína. A avaliação visual indicou o tipo de interação denominada miscibilidade, pois não foi constatado separação de fases. A microscopia ótica confirmou os dados com a ausência de formação de complexos para todos os pares avaliados e, como na reologia, constatou que a aplicação de ultrassom ocasionou a diminuição de tamanho das partículas, mesmo as soluções sendo aparentemente diluídas.
\end{abstract}

\section{INTRODUÇÃo}

Biopolímeros como proteínas e polissacarídeos estão presentes em conjunto em muitos tipos de sistemas alimentícios. O concentrado proteico de soro de leite é um ingrediente importante devido às suas propriedades funcionais desejáveis: solubilidade em água, aumento de viscosidade, gelificação, emulsificação, aeração, melhoria da cor, textura e flavor, além do aumento do valor nutricional de formulações (KREŠIĆ et al. 2008). A pectina constitui-se em um coloide por excelência, e em função de seu caráter hidrofílico, devido à presença de grupos polares, apresenta a propriedade de envolver grande quantidade de água, produzindo uma solução viscosa, sendo utilizada em alimentos como espessante, texturizante, emulsificante ou estabilizante (BOWERS, 1992).

Misturas de proteínas e polissacarídeos em determinadas condições resultam em separação de fases e, dependendo do tipo de interação existente entre eles, as interações podem ser associativas ou segregativas, 
dentre elas há a miscibilidade, a incompatibilidade e a coacervação complexa (DE KRUIF; TUINIER, 2001).

Essas separações de fases são interessantes para a criação de novas estruturas porque a adição de polissacarídeos, mesmo em baixas concentrações, pode criar grandes diferenças na estrutura e nas propriedades reológicas, além da possibilidade de indução de grandes diferenças na consistência ou textura com apenas pequenos efeitos em outras propriedades organolépticas (RENARD; VAN DE VELDE; VISSCHERS, 2006).

Além disso, a funcionalidade das proteínas pode ser afetada pela aplicação do ultrassom de alta intensidade, como resultado da cavitação, aquecimento, agitação dinâmica, tensão de cisalhamento e turbulência atingida nas vizinhanças dos pontos de cavitação. $\mathrm{O}$ rápido colapso das bolhas produz forças de cisalhamento grandes $\mathrm{o}$ suficiente para romper ligações covalentes em materiais poliméricos que estejam dissolvidos no meio (ARZENI et al., 2012).

Sendo assim, o objetivo deste estudo foi avaliar a interação eletrostática entre concentrado proteico de soro e pectina de alto teor de metoxilação por meio de medidas reológicas, microscopia ótica e avaliação visual, verificando o efeito da aplicação de ultrassom e de diferentes proporções entre a mistura de biopolímeros.

\section{MATERIAIS E MÉTODOS}

Os biopolímeros utilizados foram pectina de alto teor de metoxilação (PEC HMP) (Danisco Brasil Ltda) e concentrado proteico de soro (WPC) (80 HS, Alibra Ingredientes).

Soluções estoque de proteína (WPC) e de polissacarídeo (PEC) ambas, na concentração de $2 \%(0,02 \mathrm{~kg} / \mathrm{kg})$ foram preparadas em solução tampão $\mathrm{pH} 3,5$ de Mcllvaine (fosfato dissódico - ácido cítrico)
(GOMORI, 1955) mantidas em agitação por 3 horas e deixadas em repouso por 12 horas em temperatura ambiente para garantir completa hidratação. Todas as soluções foram adicionadas de azida de sódio, 0,03 \% (0.0003 $\mathrm{kg} / \mathrm{kg}$ ) para prevenir o crescimento microbiano.

Sistemas mistos foram obtidos pela mistura de massa apropriada das soluções estoque de modo a resultar nas concentrações desejadas de WPC:PEC nas proporções 1:1; $2: 1 ; 3: 1 ; 4: 1$ e $5: 1$ com e sem aplicação de ultrassom (Sonic Ruptor 4000, Omni International, EUA) a uma frequência de 20 $\mathrm{kHz}$ por 5 minutos de forma contínua com potência de $320 \mathrm{~W}$. As misturas foram preparadas em triplicata em tubos de ensaio com uma quantidade de polímero total fixada em 2,0 \% (p/p), totalizando 10 amostras distintas. Todas as amostras permaneceram em repouso por no mínimo 24 horas para que ocorresse a interação. Essas amostras foram submetidas à avaliação visual, ensaios reológicos e microscopia ótica.

A avaliação visual foi realizada após as 24 horas de repouso, onde foram registradas fotos de todos os tubos de ensaio para posterior análise.

O comportamento reológico dos complexos foi avaliado em um reômetro rotacional AR-2000EX (TA Instruments, Delaware, USA), utilizando geometria do tipo placas paralelas ranhuradas $(40 \mathrm{~mm}) \mathrm{com}$ um gap de $300 \mu \mathrm{m}$, segundo as características das amostras. O comportamento reológico dos complexos foi avaliado obtendo-se curvas de tensão-deformação, com rampa descendente $\left(100 \mathrm{a}_{\left.0,1 \mathrm{~s}^{-1}\right)}\right)$ e rampa ascendente $\left(0,1 \mathrm{~s}^{-1} \mathrm{a}\right.$ 100) com temperatura fixa de $25^{\circ} \mathrm{C}$. A equação 1 (modelo reológico da Lei da Potência) foi ajustada às curvas de escoamento, permitindo o cálculo dos parâmetros reológicos, os quais puderam ser correlacionados em função da composição do sistema. 
$\tau=\mathrm{K} \dot{\gamma}^{n}$

A morfologia dos sistemas foi avaliada em microscópio ótico (Olympus CX31, SC30) com câmara de vídeo acoplada para captura e digitalização das imagens com lente de 10x de aumento.

\section{RESULTADOS E DISCUSSÃO}

\subsection{Avaliação Visual}

O sistema WPC:PEC sem e com aplicação de ultrassom (U) não mostrou separação de fases, como mostra a Figura 1. Isso confirma o tipo de interação denominada miscibilidade, onde o sistema permanece homogêneo, não existindo separação de fases. Neste caso, os diferentes biopolímeros agem como se fossem hidrocoloides do mesmo tipo e este tipo de situação geralmente ocorre para soluções diluídas (SCHMITT et al., 1998).

Figura 1: Influencia do $\mathrm{pH} 3,5$ e das proporções de biopolímeros WPC:PEC no aspecto visual. Imagens após 24 horas de repouso. A letra $U$ indica as amostras com aplicação de ultrassom.

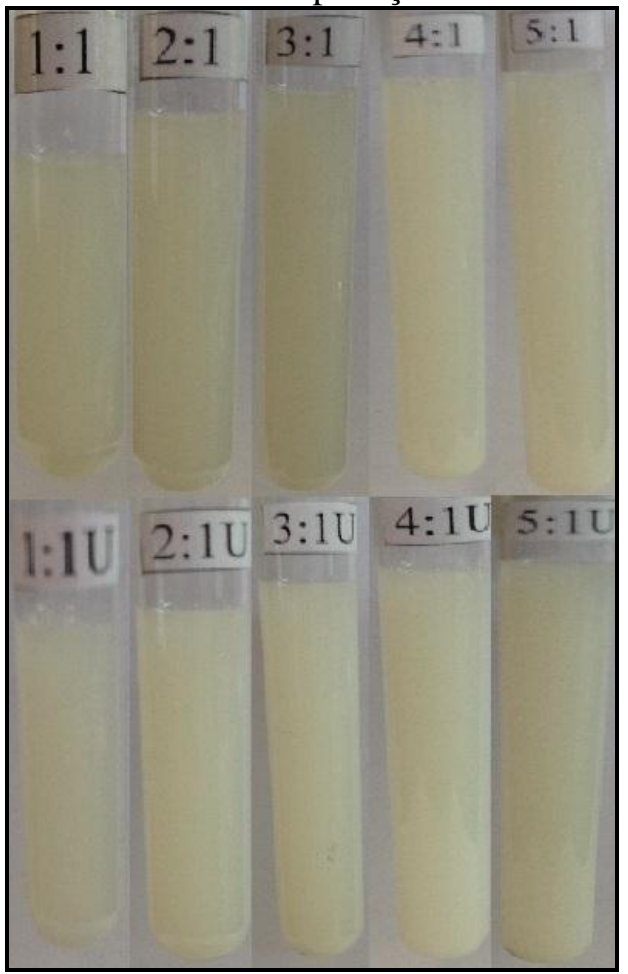

Camilo (2007) avaliou a interação de pectina de alta metoxilação com a caseína por meio da mobilidade eletroforética e encontrou que em $\mathrm{pH}$ próximo de 4,0 haveria maior interação. Foi demonstrado que nestes sistemas, no intervalo de $\mathrm{pH}(4,0-5,3)$ a pectina adsorve na superfície das micelas de caseína presentes no leite, evitando a floculação e agregação das mesmas. Porém, isto só ocorre nesta faixa de $\mathrm{pH}$ próximo ao $\mathrm{pI}$ da proteína, onde as mesmas se encontram com um balanço de cargas opostas, promovendo a adsorção do polissacarídeo.

Em um estudo foi avaliado a melhora das propriedades funcionais com a interação de WPC com a pectina e concluiu-se que a formação de complexos de proteínapolissacarideo é um método valioso para controlar as propriedades físico-químicas das proteínas. No presente estudo, as propriedades funcionais, como a solubilidade, emulsificação, gelificação e espuma o comportamento do WPC parecia melhorar quando combinado com o aumento com pectina. Por isso, complexos de proteínapolissacarídeo pode ser considerados como uma alternativa para melhorar a aplicabilidade do WPC na indústria de alimentos (MISHRA, MANN, JOSHI, 2001).

\subsection{Comportamento Reológico}

O modelo lei da Potência ajustou-se bem aos dados $\left(\mathrm{R}^{2}=0,9\right)$ para todos os pares estudados e não houve variação significativa dos valores $\mathrm{K}$ e $\mathrm{n}$ da rampa descendente (rampa 1) para a rampa ascendente (rampa 2). Os valores do índice de consistência $(\mathrm{K})$, índice de comportamento (n) e coeficiente de determinação $\left(\mathrm{R}^{2}\right)$ na temperatura de $25{ }^{\circ} \mathrm{C}$ para os diferentes pares de biopolímeros em suas diferentes proporções sem aplicação de ultrassom estão apresentados na Tabela 1 e com aplicação de ultrassom (U) estão apresentados na Tabela 2. 
O par WPC:PEC apresentou o seguinte comportamento: $\mathrm{K}$ diminuiu com o aumento da proporção de proteína para todas as amostras, sonificadas ou não, e as sonificadas seus valores foram próximos ou inferiores às não sonificadas. $O$ índice de comportamento indicou comportamento pseudoplástico $(n<1)$, no entanto, esteve muito próximo de $1(\mathrm{n}=0,9)$ tendendo ao comportamento newtoniano. As curvas de escoamento da rampa 1 para rampa 2 não apresentaram diferença significativa, indicando não haver comportamento tixotrópico e dessa forma são apresentadas as rampas 1 e 2 somente nas proporções 1:1 e 2:1 como mostra a Figura 2.

Tabela 1: Valores do índice de consistência (K), índice de comportamento (n) e coeficiente de determinação $\left(\mathrm{R}^{2}\right)$ na temperatura de $25{ }^{\circ} \mathrm{C}$ para os diferentes pares de biopolímeros em suas diferentes proporções sem aplicação de ultrassom.

\begin{tabular}{|c|c|c|c|}
\hline \multicolumn{4}{|c|}{ Sem aplicação de ultrassom } \\
\hline \multirow{2}{*}{ WPC:PEC } & \multicolumn{3}{|c|}{ Rampa 1} \\
\hline & $\mathbf{K}(\mathbf{P a})$ & n & $\mathbf{R}^{2}$ \\
\hline 1:1 & 0.014 & 0.921 & 0.999 \\
\hline $2: 1$ & 0.005 & 0.956 & 0.999 \\
\hline $3: 1$ & 0.003 & 0.948 & 0.999 \\
\hline $4: 1$ & 0.002 & 0.966 & 0.999 \\
\hline $5: 1$ & 0.001 & 0.955 & 0.999 \\
\hline \multirow{2}{*}{ WPC:PEC } & \multicolumn{3}{|c|}{ Rampa 2} \\
\hline & $\mathbf{K}(\mathbf{P a})$ & n & $\mathbf{R}^{2}$ \\
\hline $1: 1$ & 0.014 & 0.927 & 0.999 \\
\hline $2: 1$ & 0.005 & 0.959 & 0.999 \\
\hline $3: 1$ & 0.003 & 0.949 & 0.999 \\
\hline $4: 1$ & 0.002 & 0.970 & 0.999 \\
\hline $5: 1$ & 0.001 & 0.963 & 0.999 \\
\hline
\end{tabular}

$\mathrm{O}$ fato de este sistema apresentar valores de $\mathrm{n}$ mais elevados e $\mathrm{K}$ não aumentar com o aumento da proporção de proteína, que é uma solução mais diluída, pode estar relacionado justamente pelo aumento de solução aquosa no sistema, pois como a viscosidade da solução de pectina a $2 \%$ $(0,02 \mathrm{~kg} / \mathrm{kg})$ é baixa, com a junção da solução de proteína não houve grandes interações, independente da proporção havendo somente um aumento no volume das soluções e uma miscibilidade das mesmas. $\mathrm{O}$ sistema WPC:PEC mostrou a influência da pectina na interação e embora tenha apresentado comportamento pseudoplástico, teve tendência ao Newtoniano, mostrando coerência com as amostras e as imagens obtidas, que mostraram miscibilidade, onde não há separação de fases visível e uma solução diluída, motivo este que não foi possível realizar ensaios oscilatórios.

Tabela 2: Valores do índice de consistência (K), índice de comportamento (n) e coeficiente de determinação $\left(\mathrm{R}^{2}\right)$ na temperatura de $25{ }^{\circ} \mathrm{C}$ para os diferentes pares de biopolímeros em suas diferentes proporções com aplicação de ultrassom (U).

\begin{tabular}{cccc}
\hline \multicolumn{4}{c}{ Com aplicação de ultrassom } \\
\hline \multirow{2}{*}{ WPC:PEC } & \multicolumn{3}{c}{ Rampa 1 } \\
& K (Pa) & n & $\mathbf{R}^{\mathbf{2}}$ \\
\hline $\mathbf{1 : 1 U}$ & 0.006 & 0.959 & 0.999 \\
$\mathbf{2 : 1 U}$ & 0.003 & 0.951 & 0.999 \\
$\mathbf{3 : 1 U}$ & 0.002 & 0.964 & 0.999 \\
$\mathbf{4 : 1 U}$ & 0.001 & 0.960 & 0.999 \\
$\mathbf{5 : 1 U}$ & 0.002 & 0.864 & 0.994 \\
\hline \multirow{4}{*}{ Rampa $\mathbf{2}$} \\
WPC:PEC & K (Pa) & n & $\mathbf{R}^{\mathbf{2}}$ \\
\hline 1:1U & 0.006 & 0.968 & 0.999 \\
2:1U & 0.003 & 0.950 & 0.999 \\
3:1U & 0.002 & 0.972 & 0.999 \\
4:1U & 0.001 & 0.977 & 0.999 \\
5:1U & 0.002 & 0.869 & 0.996
\end{tabular}

Piazza et al. (2009) estudou soluções compostas de água que foram preparadas com a seguinte composição: $0,1 \%$ w/w concentração constante de proteína de soja com $0,1,0,5$ e $1 \%$ w/w de pectina HMP. Todas as soluções apresentaram um comportamento Newtoniano na faixa de taxa de cisalhamento investigado (1-1000 $\left.\mathrm{s}^{-1}\right)$.

Perez et al. (2011) estudou o comportamento adsorção dinâmico (pressão de superfície e reologia de superfície dilatacional) de biopolímeros puros e misturas de proteína de soro de leite com pectina e 
constatou que as características interfaciais da pectina exerceu uma grande influência sobre o comportamento da adsorção da proteína de soro de leite na interface ar-água.

Figura 2: Efeito da aplicação de ultrassom ( $\mathbf{\Delta}$ ) e não aplicação do ultrassom (অ) nas proporções 1:1 (a), 2:1 (b), 3:1 (c), 4:1 (d) e 5:1 (e) e ajuste do modelo lei da potencia das curvas de escoamento descendente do par WPC:PEC.

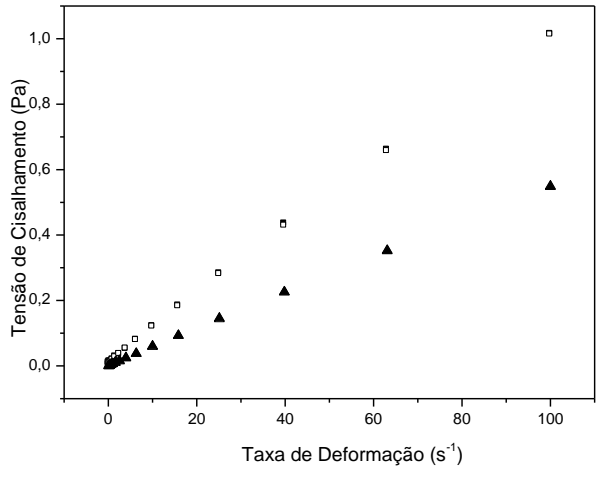

(a)



(c)

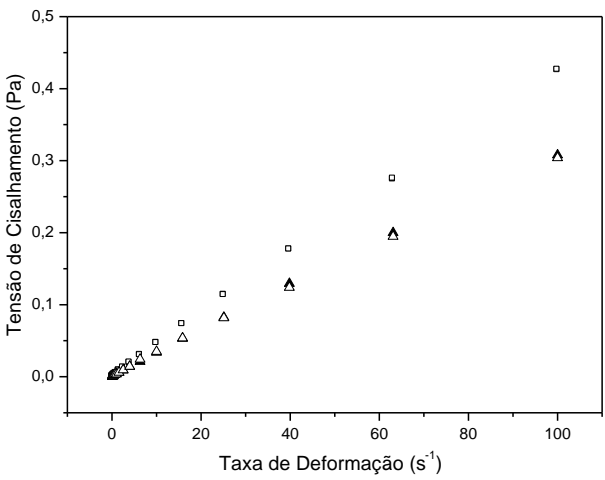

(b)

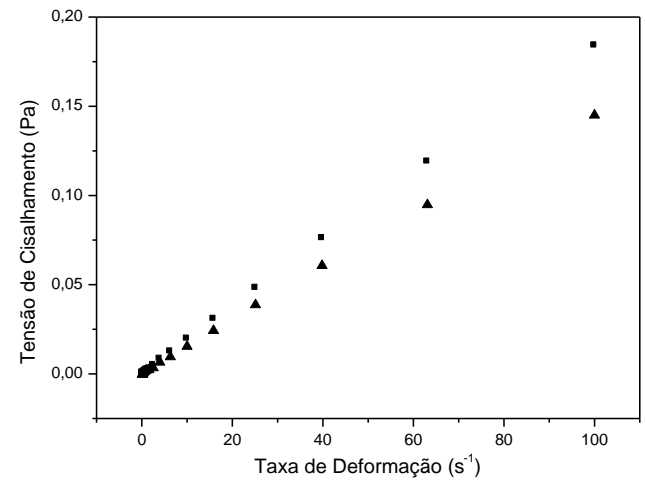

(d)

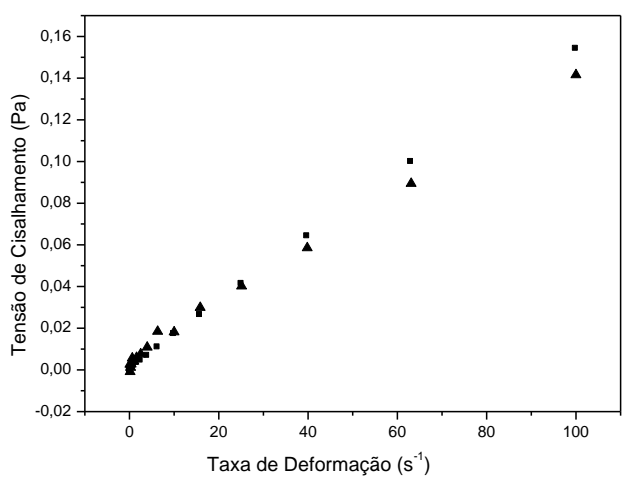

(e) 


\section{ENEMP \\ (1) \\ DE SISTEMAS PARTICULADOS \\ São Carlos - SP}

É possível observar que a aplicação do ultrassom ocasionou menores tensões de cisalhamento, onde a rampa das amostras sonificadas foram todas inferiores às não sonificadas, indicando que, mesmo a solução sendo aparentemente diluída, o ultrassom ocasionou a diminuição de tamanho das partículas.

\subsection{Microscopia Ótica}

As imagens obtidas por microscopia ótica do sistema WPC:PEC preparado com e sem sonificação mostram a ausência de complexos formados entre os biopolímeros, como mostra a Figura 3, assim como foi observado na avaliação visual dos tubos do item 3.1.

O par WPC:PEC mostra praticamente a ausência de complexos formados, indicando

Figura 3: Imagens dos complexos do par WPC:PEC nas diferentes proporções com e sem aplicação de ultrassom nas lentes de 10x de aumento $(50 \mu \mathrm{m})$.

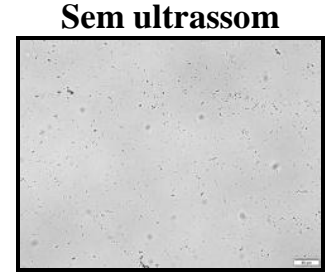

$1: 1$

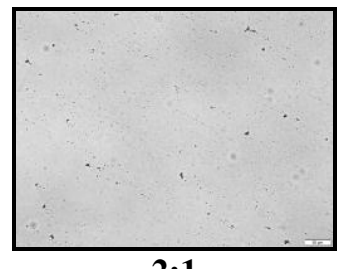

$2: 1$

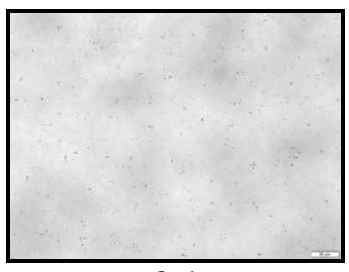

$3: 1$

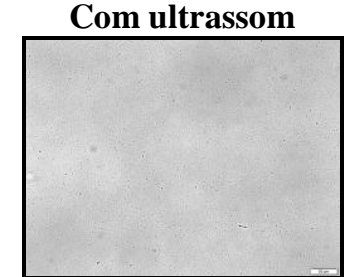

$1: 1 \mathrm{U}$

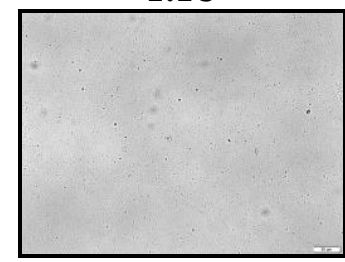

2:1U

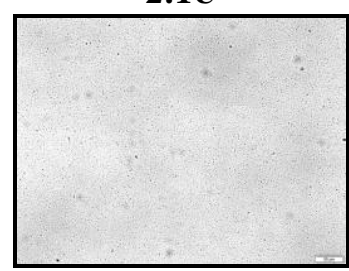

3:1U

\section{CONCLUSÃO}

O par SPI:PEC mostrou comportamento de miscibilidade, onde há ausência de

uma solução diluída e miscível, isto explica o motivo de ser impossível obter espectros mecânicos e porquê no cisalhamento constante os dados tenderam ao comportamento Newtoniano, com $\mathrm{K}$ muito baixo e $\mathrm{n}$ tendendo a 1 . As imagens óticas também comprovam, embora discretamente, que o ultrassom ocasionou a diminuição das partículas existentes no sistema. Estudos de ultrassom são aplicados diretamente para modificar as propriedades físicas e funcionais de proteínas: tais como solubilidade, gelificação, emulsificação e capacidade de espuma (HU et al., 2013). Mu et al. (2010) relataram que o tratamento de ultrassom foi um método eficiente para a formação de conjugados de proteínas e polissacarídeos.

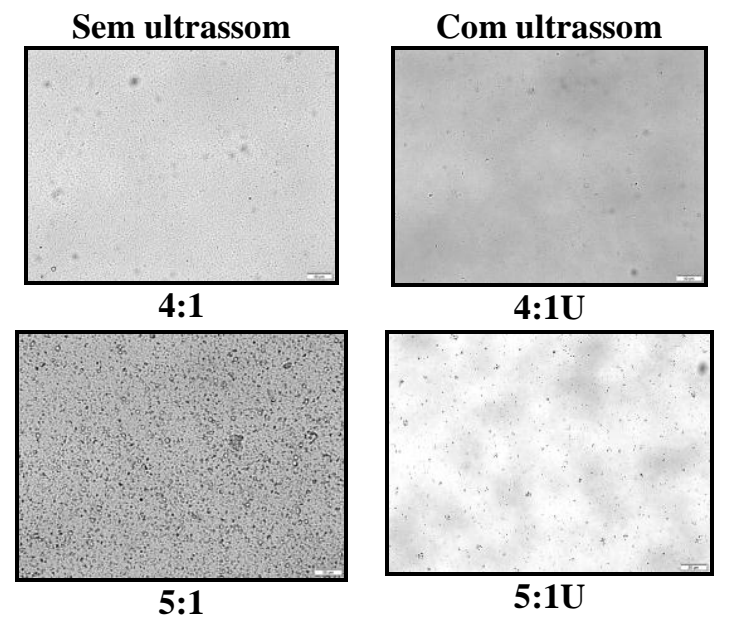

complexos, apresentando ligeira pseudoplasticidade, tendendo a um comportamento Newtoniano para todos os pares avaliados. A aplicação de ultrassom reduziu o tamanho das partículas 
independente do aumento da proporção de proteína, onde permaneceram em solução sem separação de fases. Essas observações são de relevância, pois mesmo que visivelmente não há alterações no sistema, o ultrassom pode modificar as propriedades físicas e funcionais dos biopolímeros, melhorando sua aplicabilidade.

\section{NOMENCLATURA}

$\tau$ : Tensão de cisalhamento (Pa.s)

$\dot{\gamma}$ : taxa de deformação $\left(\mathrm{s}^{-1}\right)$

$\mathrm{K}$ : Índice de consistência $(\mathrm{Pa})$

$\mathrm{n}$ : Índice de comportamento (adimensional)

WPC: Concentrado Proteico de Soro

PEC: Pectina

\section{REFERÊNCIAS}

ARZENI, C.; MARTÍNEZ, K.; ZEMA, P.; ARIAS, A.; PÉREZ, O. E.; PILOSOF, A.M.R.Comparative study of high intensity ultrasound effects on food proteins functionality. Journal of Food Engineering, v. 108, p. 463-472, 2012.

BOWERS, J. Food Theory and Aplications. $2^{\mathrm{a}}$ Ed. New York: Macmillan Publishing Company, 411p. 1992.

CAMILO, K. F. B. Complexo pectina/caseína: aspectos básicos e aplicados. 2007. 147p. Tese (Doutorado em Ciências Farmacêuticas) - Universidade de São Paulo, USP, Ribeirão Preto, 2007.

DE KRUIF, C. G.; TUINIER, R. Polysaccharide protein interactions. Food Hydrocolloids, v.15, p.555-563, 2001.

GOMORI, G.. Preparation of buffers for use in enzyme studies. Methods in Enzymology, vol.1, pp. 138-146, 1955.
HU, H.; WU. J.; LI-CHAN, E. C. Y.; ZHU, L.; ZHANG, F.; XU, X.; FAN, G.; WANG, L.; HUANG, X.; PAN, S. Effects of ultrasound on structural and physical properties of soy protein isolate (SPI) dispersions. Food Hydrocolloids v.30, p. 647-655, 2013.

KRESIC, G.; LELAS, V.; JAMBRAK, A. R.; HERCEG, Z.; BRNIC, S. R. Influence of novel food processing technologies on the rheological and thermophysical properties of whey proteins. Science Direct, v. 87, p. 6473, 2008.

MISHRA, S., MANN, B., JOSHI, V.K. Functional improvement of whey protein concentrate on interaction with pectin. Food Hydrocolloids v.15, p. 9-15, 2001.

MU, L.; ZHAO, M.; YANG, B.; ZHAO, H.; CUI, C.; ZHAO, Q. Effect of ultrasonic treatment on the graft reaction between soy protein isolate and gum acacia and on the physicochemical properties of conjugates. Journal of Agricultural and Food Chemistry, v.58, p.4494-4499, 2010.

PEREZ, A. A.; SÁNCHES, C. C.; PATINO, J. M. R.; RUBIOLO, A. C.; SANTIAGO, L. G. Surface adsorption behaviour of milk whey protein and pectin mixtures under conditions of air-water interface saturation. Colloids and Surfaces B: Biointerfaces, v.85. p. 306315, 2011.

PIAZZA, L.; DURR-AUSTER, N.; GIGLI, J.; WINDHAB, E. J.; FISCHER, P. Interfacial rheology of soy proteins - high methoxyl pectin films. Food Hydrocolloids, v.23, p. 2125-2131, 2009.

RENARD, D.; VAN DE VELDE, F.; VISSCHERS, R. W. The gap between food gel structure, texture and perception. Food Hydrocolloids, v. 20, p.423-431, 2006. 
SCHMITT, C.; SANCHEZ, C., DESOBRYBANON, S., HARDY, J. Structure and Techno functional Properties of ProteinPolysaccharide Complexes: A Review. Critical Reviews in Food Science and Nutrition, v.38, n. 8, p. 689-753, 1998.

\section{AGRADECIMENTOS}

À FAPESP (Processos. 2013/10842-9 e 2014/02910-7). À Danisco Brasil Ltda pela doação da pectina HMP e à Alibra Ingredientes pela doação do concentrado proteico de soro. 